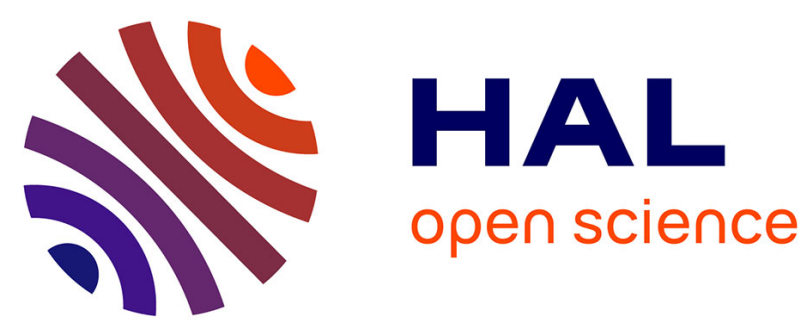

\title{
Bladder cancer and occupational exposure to metalworking fluid mist: a counter-matched case-control study in French steel-producing factories
}

Régis Colin, Michel Grzebyk, Pascal Wild, Guy Hédelin, Eve Bourgkard

\section{To cite this version:}

Régis Colin, Michel Grzebyk, Pascal Wild, Guy Hédelin, Eve Bourgkard. Bladder cancer and occupational exposure to metalworking fluid mist: a counter-matched case-control study in French steel-producing factories. Occupational and Environmental Medicine, 2018, 75 (5), pp.328-336. 10.1136/oemed-2017-104666 . hal-02006663

\section{HAL Id: hal-02006663 https://hal.science/hal-02006663}

Submitted on 4 Feb 2019

HAL is a multi-disciplinary open access archive for the deposit and dissemination of scientific research documents, whether they are published or not. The documents may come from teaching and research institutions in France or abroad, or from public or private research centers.
L'archive ouverte pluridisciplinaire HAL, est destinée au dépôt et à la diffusion de documents scientifiques de niveau recherche, publiés ou non, émanant des établissements d'enseignement et de recherche français ou étrangers, des laboratoires publics ou privés.

\section{(ㄷ)(1) $\$$}

Distributed under a Creative Commons Attribution - NonCommerciall 4.0 International 
Bladder cancer and occupational exposure to metalworking fluid mist: a counter-matched case-control study in French steel-producing factories.

Régis Colin ${ }^{1}$, Michel Grzebyk $^{1}$, Pascal Wild², Guy Hédelin ${ }^{1}$, Eve Bourgkard ${ }^{1 *}$

* Correspondence to Eve Bourgkard, Department of Occupational Epidemiology, Occupational health and safety Institute (INRS), 1, rue du Morvan - CS 60027 - 54519 Vandœuvre -les-Nancy, France (e-mail: eve.bourgkard@inrs.fr)

Authors affiliations:

${ }^{1}$ Department of Occupational Epidemiology, Occupational health and safety Institute (INRS), Vandœuvre-les-Nancy, France

${ }^{2}$ Department of Scientific Management, Occupational health and safety Institute (INRS), Vandœuvre-les-Nancy, France

KEYWORDS: bladder cancer; metalworking fluids; counter-matching. 


\section{ABSTRACT:}

\section{Objectives}

To assess the relationship between occupational exposure to metalworking fluids (MWFs) in the steel-producing industry and bladder cancer incidence.

\section{Methods}

A nested case-control study on bladder cancer was set up in a cohort of workers from six French steel-producing factories. Three controls were randomly selected for each incident bladder cancer case diagnosed from 2006-2012. Controls were matched to cases on age at diagnosis and counter-matched on a surrogate measure of exposure to MWFs derived from a job-exposure matrix. Cases $(n=84)$ and controls $(n=251)$ were face-to-face interviewed. Experts assessed occupational exposure to MWFs (straight, soluble, synthetic) using questionnaires and reports from factory visits. Occupational exposures were based on three metrics: duration, frequency-weighted duration, cumulative exposure index. Conditional multiple logistic regressions were used to determine Odds-Ratios and Confidence Intervals (CI95\%), taking non-occupational and occupational exposure into account.

\section{Results}

In the 25 years before diagnosis, ORs increased significantly with duration of exposure to straight MWFs (OR=1.13 [1.02-1.25]) and increased with frequency-weighted duration of exposure to straight MWFs (OR=1.44 [0.97-2.14]). These results remained valid after adjusting for duration of smoking, average number of cigarettes smoked per day, time since smoking cessation and exposure to polycyclic aromatic hydrocarbons (PAH). ORs also increased with soluble MWFs, but not significantly. No significant association was found with older exposures to MWFs or with exposure to synthetic MWFs. 


\section{Conclusion}

Our findings may be explained by the presence of carcinogens (such as $\mathrm{PAH}$ ) in mineral oils principal component of straight oils. Prevention therefore remains necessary in sectors using MWFs.

Word count: 250 (250)

\section{WHAT THIS PAPER ADDS?}

\section{What is already known about this subject?}

Historically, metalworking fluids (MWFs) have been linked to increased incidence of bladder cancer. However, changes to composition and practices call for an updated study.

\section{What are the new findings?}

This counter-matched case-control study aimed at assessing the relationship between occupational exposure to MWFs in the steel-producing industry and bladder cancer risk. Occupational exposures to straight MWFs in the last 25 years appear to have an effect on bladder cancer incidence. Our study cannot exclude a relationship with exposure to soluble MWFs and does not detect any relationship with synthetic MWFs.

3. How might it impact on policy or clinical practice in the foreseeable future?

Our findings may be explained by the presence of carcinogens (such as PAH) in mineral oils principal component of straight oils. Prevention therefore remains necessary in sectors using MWFs. 


\section{ORIGINAL ARTICLE:}

Metalworking fluids (MWFs) are used during metal working processes, electroerosion, metal deformation, molding operations to lubricate, cool and remove debris from the surface of the workpiece. MWFs can be classified based on their composition: (i) straight MWFs (mineral oil, no water); aqueous MWFs including (ii) soluble MWFs (mineral oil emulsified in water), and (iii) synthetic MWFs (water with soluble compounds, no mineral oil). MWFs contain additives, such as lubricants, extreme-pressure resistant, antimisting, antiwear, and coloring agents, corrosion inhibitors, biocides, biostatics or perfumes [1]. When using MWFs, aerosols of cutting fluids, known as oil mist, are generated. These aerosols may remain airborne for several hours, and are often present in workers' breathing zones. The tiny, floating droplets making up these aerosols contain both the basic ingredients of MWFs and derivatives produced by thermal degradation. In addition, they can contain machined materials, or microorganisms when using aqueous fluids [1]. Among these elements, some known or suspected carcinogens have been identified, such as polycyclic aromatic hydrocarbons (PAHs) and nitrosamines [2].

In 1984, according to the International Agency of Research on Cancer (IARC), "there [was] sufficient evidence from studies in humans that mineral oils (containing various additives and impurities) that have been used in occupations such as mulespinning, metal machining and jute processing are carcinogenic to humans". Exposure in these occupations "[has] been associated strongly and consistently with the occurrence of squamous-cell cancers of the skin, and especially of the scrotum" $[3,4]$. In the literature, an increased risk of bladder cancer has been reported for machinists and mechanics, both personnel categories using MWFs [3, 4]. Most of these studies relate to relatively old (prior to the mid-1990s) 
employment periods. However, more recent follow-up and exposure studies also reported an increased risk of bladder cancer among workers exposed to oil mist [5-9]. The composition and nature of MWFs have changed in recent decades, with reductions in the PAH content of straight MWFs from the mid-1980s [10]. However, chemical analyses continue to show PAH enrichment or significant concentrations of nitrosamines in MWF aerosols [11]. Since the last quarter of the $20^{\text {th }}$ century, aqueous MWFs were increasingly used, representing 37\% of MWFs used in France in 1970 compared to $49 \%$ in 2009. Simultaneously, the proportion of straight MWFs sold decreased from $63 \%$ to $51 \%[12,13]$. Current data do not allow us to determine whether these changes contributed to a decreased incidence of bladder cancer $[14,15]$.

In a previous study of mortality in French steel-producing factories, we assessed occupational exposure based on a factory-specific job-exposure matrix (JEM)[5]. Secondary results indicated excess mortality from bladder cancer for workers exposed to oil mist $(\mathrm{RR}=2.44,95 \% \mathrm{Cl}=1.06-5.60)[5]$.

Based on these findings, it appears necessary to identify and quantify the risk of bladder cancer associated with the different types of MWFs to which workers may be exposed, particularly since the mid-80s.

In this paper, we report the findings of a nested case-control study involving a cohort of workers from six French steel-producing factories. The study was designed to assess possible relationships between occupational exposure to the three types of MWFs and the risk of bladder cancer, taking occupational and non-occupational factors into account.

\section{MATERIALS AND METHODS}

\section{- Study population}


The cohort included 22,795 male workers from six French steel-producing factories, employed for at least 1 year in the same factory, between January 1960 and June 1997. Data from two of the six factories (initial cohort 1) were gathered during our previous study [5]. For the remaining four factories (initial cohort 2), cohort members were identified based on payroll records. The cohort included workers from the whole steel-manufacturing chain (coke oven, sintering, blast furnace, steel mill, sheet mill, cold rolling mill, hot rolling mill, and pipe mill), as well as support departments (materials and supplies, maintenance, transport, research, administration). Incident cases and controls were selected from this cohort. All confidentiality, safety and security procedures were approved by the French legal authorities.

\section{- $\quad$ Cohort-based estimation of MWF exposure: a surrogate for MWF exposure}

In our previous study [5], a JEM including semi-quantitative assessment of exposure to MWFs was set up for two of the six factories. The same JEM was used for the four other factories to assess the correspondence between periods of work at the four factories and MWF exposure. The pipe and cold rolling mills were not included in the JEM, but the corresponding job titles were related to the most relevant MWFs job-exposure periods.

For each subject in the cohort, a surrogate cumulative exposure index was calculated, by summing the product of duration and intensity of exposure for each job, considering a tenyear lag [6] from the age at bladder cancer diagnosis expected according to French incidence rates (68 years). Four MWF-exposure strata were defined based on the distribution of the surrogate cumulative index for all cohort members. Since a large number of subjects were not exposed to MWF, level zero was considered as the "non-exposed" class. The three other classes were defined by the tertiles of the non-zero surrogate cumulative index. 


\section{- $\quad$ Case ascertainment}

Cases were defined as any men in the cohort diagnosed with primary bladder tumor (both invasive tumors and in situ carcinomas) during the 2006-2012 period. Follow-up was retrospective before 2010, and prospective from 2010. Cancer cases were classified based on the WHO International Classification of Diseases for Oncology, Third Edition (ICD-O-3). Cases were identified by matching the identity data of the cohort subjects, using ICD-codes (C670 to C679), with two sources of information: (i) the clinical information databases from all the hospitals and clinics within a $50-\mathrm{km}$ radius of the factories; and (ii) the national records of requests for exemption from medical expenses through which the French health care system waives payment for treatment for patients with long-term diseases, including cancers. Date of cancer diagnosis, topography, morphology, cancer staging and cell grade were obtained from patients' medical files to verify that the diagnosis of bladder cancer had been histologically validated. To be included in this study, cases had to be alive on the date of interview.

\section{- Control selection}

For each case, a risk set was set up consisting in all cohort members at risk at the age of diagnosis of the case whatever the date and belonging to the same initial cohort than the case (online figure 1).

Within each risk set, and for each subject, a surrogate cumulative exposure index corresponding to the sum of the product of exposure duration and intensity for each job, up to a reference date, with a 10-year lag, was calculated using the surrogate estimation of MWF exposure. The reference date corresponded to the date of diagnosis for cases and to 
the date on which matched controls reached the age of the case at diagnosis. All workers of the risk set were assigned to one of the four surrogate exposure strata previously defined (online figure 1).

Three controls, alive at the date of data collection, were randomly selected from the risk set, counter-matched on the MWF surrogate exposure strata $[16,17]$ (online figure 1 ). This counter-matching involves selection of three controls who have a different occupational surrogate exposure level from the case and from one another at the age of the case at diagnosis [18]. Thus, each of the three controls and the case belonged to a different stratum. The sampling weights used for the statistical analysis of these data are the stratum-wise numbers of the risk set members, whether alive or not at the date of data collection.

\section{- Data collection}

Cases and controls received a letter explaining the objective of the study, the modalities of participation, and information for an appointment. Participants signed written informed consent forms before the interview was conducted.

Participants were interviewed face-to-face at home by trained staff using a series of questionnaires. One questionnaire covered socio-demographic characteristics and medical histories, in particular regarding chronic bladder diseases, personal or family history of cancer, chronic bladder irritations (urinary schistosomiasis or urolithiasis), and abdominopelvic radiography.

Non-occupational parameters were also recorded: smoking and drinking habits, and fruit and vegetable consumption. Environmental arsenic exposure in drinking-water was determined from residential history. 
A full occupational history was gathered by collecting detailed information on the jobs held for at least 1 month throughout the subject's career. For each job, the main tasks performed and the company's activity were described. A questionnaire relating to 43 tasks potentially involving exposure to bladder carcinogens (aromatic amines, PAHs) was used [19].

Moreover, for each job within the 17 steel-producing or maintenance sectors identified, a sector-specific questionnaire focused on the activities performed. Thus, detailed information was collected about tasks exposing to atmospheric $\mathrm{PAH}$, exposure to solvents (type and conditions of use), exposure to MWFs - including nature and appearance of the fluids (oily, milky or transparent) - tasks performed, use of personal protective equipment, use of collective protective equipment, and type of machining-tools used.

During on-site visits, information was collected on exposure for present and past processes, working conditions and ventilation systems, and the MWFs used (as determined from the safety data sheets in each workshop for each factory for the 1980-2010 period).

\section{- Assessing occupational exposure in cases and control}

Present and past occupational exposures were coded by two experts (one senior occupational hygienist and one senior occupational epidemiologist) with a thorough understanding of the processes and history of each facility. For each subject, exposure was assessed for all jobs occupied (job title, workplace, start date, end date) during his career. Experts were blind to case and control status when gathering this data from the available occupational information: responses to occupational questionnaires, site visit reports, and the list of fluids and oils used in each workshop.

The following occupational exposures were coded: MWFs, PAHs except MWFs, chlorinated solvents, nitrosamines, and diesel exhaust fumes. Depending on occupational exposure 
levels, up to four exposure indicators were coded: presence, intensity, nature and frequency of exposure. An exposure intensity code on a 0-1-2 scale was defined for MWFs, and chlorinated solvents, and on a 0-1-2-3 scale for PAHs. For nitrosamines and diesel exhaust fumes, only the presence of exposure could be recorded. To assess the intensity of exposure to MWFs, experts identified several typical jobs associated with different intensity levels (online table 1). These typical jobs were used as coding benchmarks. For PAHs, the correspondence between job period and intensity code in the JEM from our previous study [5] was used as a reference. Moreover, intensity levels were confirmed by the experts based on responses to the occupational questionnaires, and were adjusted if personal or collective protective equipment was used. Information on exposure to chlorinated solvents and diesel exhaust fumes was collected during the interview.

The nature of MWFs (straight oils, soluble oils, and synthetic fluids) was obtained from multiple sources: questionnaires, workshop visits and safety data sheets.

The exposure frequency was coded as $<10 \%, 10-50 \%$ and $>50 \%$ based on the proportion of working time during which workers were exposed.

Occupational exposure was explored using three different metrics: duration of exposure at an intensity level $\geq 1$, frequency-weighted duration of exposure (sum of duration $x$ frequency), and cumulative exposure index (sum of duration $\mathrm{x}$ frequency $\mathrm{x}$ intensity).

For each case and his controls, exposure was calculated up to a reference date. For cases, the reference date was the date of diagnosis; for controls the reference date was matched to the age of the case at diagnosis.

\section{- Smoking habits}


Smokers were defined as those who had smoked more than 100 cigarettes in their lifetime and former smokers those who had quit smoking at least one year previously. The others were classed as never-smokers. Details on lifelong smoking habits were collected during the interview. Smoking was assessed based on duration of smoking, pack-years, mean number of cigarettes smoked per day and time since cessation, and summarized as a smoking status (never, former, current smoker).

\section{- Statistical analysis}

The association between risk of bladder cancer and various exposure scenarios was assessed by conditional multiple logistic regression, estimating Odds-ratios (ORs) and 95\% bilateral confidence intervals ( $95 \% \mathrm{Cls})$. To account for the counter-matched design, the logarithm of the number of subjects in the surrogate exposure strata of the risk set was incorporated as an offset when fitting the model [20].

First, to identify confounders, each non-occupational exposure index was included separately. Second, each occupational exposure index was included separately, adjusting for selected confounders (smoking duration, average cigarettes smoked per day and time since smoking cessation). Third, all occupational exposures were considered together in multiple conditional logistic regression models adjusting for the three smoking metrics. The models included the 3 types of MWFs as well as the other occupational exposures for which a $P$ value of less than 0.20 was obtained in the previous analysis. Three multiple analyses were considered, first based on duration of exposure (in year), second on frequency-weighted duration (in full-time equivalent year), and finally on cumulative exposure index (in intensity.year). 
While the selection process of the controls was based on a surrogate exposure which was lagged 10 years, the exposure metrics used in the statistical analyses were lagged 5 years. These exposure metrics further considered two time windows: 5-25 years and $25+$ years before the reference date.

Sensitivity analysis was performed by comparing different combinations of lag-duration ( $\geq 5$ years, in accordance with the empirical induction period for bladder cancer [21-23]) and exposure period using the Akaike information criterion (online figure 2). Similarly to the exposure metrics, the smoking variables were also lagged 5 years.

The threshold for significance was set at $P<0.05$. Our hypothesis was that occupational exposure effects were deleterious (OR $>1$ ), we therefore used one-tailed tests [24, 25]. All statistical analyses were performed using STATA software (StataCorp. 2014. Stata Statistical Software: Release 14. College Station, TX: StataCorp LP).

\section{RESULTS}

\section{- Study population}

Of the 157 eligible cases, 85 (54\%) were interviewed. Reasons for non-participation were death (33\%), not interested (32\%), health condition (13\%) and unreachable (22\%). For 83 of the cases interviewed, three controls per case were also interviewed. For one case, only two controls were included because no control from the third strata agreed to participate in the study. Another case was excluded from the study because of a lack of appropriate controls. Given that a single control could match several cases, the control population included 200 workers, but the overall study included 84 cases and 251 controls. The median age at diagnosis was 63.4 years. 
Among eligible cases, those who declined to participate were on average born earlier (age: 68.7 (SD, 9.0) in 2010) than those who participated (65.8 (SD, 7.5) years-old in 2010) $(P<0.05)$. Although participating cases spent longer working in the factories $(18.2$ years $(S D$, 8.3) than cases who did not participate (14.5 years (SD, 8.5)), no statistically significant difference was found between the two groups in terms of cumulative occupational surrogate exposure to MWFs.

\section{- Non-occupational characteristics of participants}

Characteristics of the cases and the controls are shown in table 1, as well as unadjusted ORs. Unadjusted ORs increased with the duration of smoking ( $p<0.001)$, the mean number of cigarettes smoked per day $(p=0.002)$ and pack-years $(p<0.001)$ and declined with time since smoking cessation $(p=0.002)$. Only two cases and two controls were exposed to environmental arsenic (data not shown). No statistically significant difference between cases and controls was observed for educational category, diet, family history of bladder cancer, personal history of chronic bladder irritation or history of abdominopelvic radiography (table 1).

\section{- Occupational exposure to MWFs and other compounds}

Taking the 5-year lag period into account, 35\% of cases had been exposed to some type of MWFs (data not shown). Exposure to PAHs other than through MWFs (except for frequencyweighted duration) was higher among cases than among controls. More than half of cases and controls were exposed to chlorinated solvents during their careers. About $15 \%$ of cases and controls were exposed to diesel exhaust fumes (table 2). Exposure to non-volatile 
nitrosamine was infrequent ( $4 \%$ of cases and $10 \%$ of controls) (data not shown). For all the occupational exposures considered, the median duration of exposure was higher among cases than controls, except for the 3 MWFs in the $\geq 25$-year time-window (table 2).

The results from conditional logistic regressions, including each occupational exposure index at a time, after adjusting for smoking habits, are presented in Tables 3 and 4 . The ORs increased with all the occupational exposure indices used in the 5-25-year time-window, except for synthetic MWFs. For straight MWFs, this increase was statistically significant whatever the exposure indices used - contrasting exposures above and below the median exposure, the OR varied between 5 and 9 (online table 2). For soluble MWFs the increases were statistically significant except for the frequency-weighted duration ( $P=0.076)$ (table 3 ) with respect to the median exposures, the OR varied between 2 and 5 (online table 2). With PAHs, ORs increased with the three exposure metrics. Chlorinated solvents also tended to increase the OR, although the increase was not statistically significant for the cumulative index, whatever the exposure indices used. Exposure to diesel exhaust fumes (ever vs. never) was not associated with increased risk (table 4).

Table 5 presents the results of the models combining the effect of exposure to the three types of MWFs adjusted for PAH and for the three smoking metrics. The hypothetical cut-off of 25 years, in line with the empirical induction period, was confirmed by the sensitivity analysis (Online figure 2) [26]. In these joint models, no significant excess risk was observed for soluble or synthetic MWFs. In contrast, the ORs increased with exposure to straight MWFs in the 5-25-year time-window whatever the index considered, and were statistically significant based on the duration of exposure in years and the weighted duration; they were not statistically significant with the cumulative exposure index (table 5). No such increase was observed for older exposures (25+ years). 


\section{DISCUSSION}

The results presented here suggest that exposure to straight MWFs is associated with an increased risk of bladder cancer between 5 and 25 years after exposure. No increase in bladder cancer was associated with exposure to soluble or synthetic MWFs. Furthermore, no association was found with exposure to MWFs before the cut-off period of 25 years, whatever the type of MWFs considered.

The exposure metrics for different MWF types were defined based on a lag of 5 years and a cut-off period of 25 years prior to the reference date, in line with the empirical induction period for bladder cancer [21-23].

Exposure to MWFs more than 25 years previously was considered as adjustment factors but was not associated with an increased risk of bladder cancer. This is consistent with the hypothesis of an empirical induction period less than 25 years or so implying that any bladder cancer attributable to MWFs would be expected to have occurred in the 25 years following exposure. Those exposures acquired prior to 25 year did not contribute materially to the risk of bladder cancer within the follow-up period; they might have contributed to the risk of bladder cancer before the follow-up period.

When comparing the mortality of the cohort to that of a local reference population, we observed a healthy worker effect which was attenuated with time since hire. We do not believe that this can have a major consequence on the case-control study.

Soluble and synthetic MWFs only gradually came into mainstream use in the last two decades, a fact which might explain the lack of association with these two types of MWFs. However, the upper limits of the confidence intervals of the OR for the soluble MWFs were 
close to the OR estimates for straight MWFs in the joint exposure models. Thus, while a risk with soluble oils cannot be excluded, it is certainly less marked than the risk with straight MWFs.

This study follows on from the secondary results of a previous mortality study conducted in French steel-producing factories assessing exposures based on a JEM [5]. A significant excess of mortality from bladder cancer was observed among workers exposed to oil mist and consistent dose-response relationships were found with highest exposure levels in the recorded work histories, durations of exposure and cumulative exposure indices. The results presented here were obtained by a different approach but they confirm the conclusion of our previous study. Moreover, this study estimated the bladder cancer risk in relation to exposure to different types of MWFs, occurring during a more recent period of time and taking smoking habits into account.

Our results are qualitatively supported by previous studies. For example, in 2009, Friesen et al. [6] showed a strong quantitative exposure-response relation between straight MWFs and bladder cancer (RR 2.07, 95\% Cl 1.19-3.62) in a cohort of autoworkers in Michigan. In 2011, Colt et al. [27] conducted a case-control study drawn from the general population of the New England states, and concluded that exposure to straight MWFs was associated with a significantly increased bladder cancer risk (OR 1.7, $95 \% \mathrm{Cl} 1.1-2.5)$. In both studies, the authors suggested that mineral oils are a bladder carcinogen. Neither study found a statistically significant excess risk of bladder cancer with soluble or synthetic MWFs. PAHs are generated during pyrolysis or from the incomplete combustion of organic matter. Some areas in steel-producing factories (coking plant, blast furnace, steelmaking plant or foundry) are associated with high PAH exposure [28]. Recent literature reviews and studies have shown an increased risk of bladder cancer in industries where workers are exposed to 
PAHs during some processes [8, 28-30]. Here, a semi-quantitative assessment of occupational PAH exposure, MWFs excluded, revealed a significantly increased incidence of bladder cancer among workers exposed to PAHs compared to non-exposed workers (table 4). These conclusions remain valid after adjusting for smoking habits and occupational exposure to MWFs (table 5).

Tobacco consumption contains multiple carcinogens, including PAHs, is the primary risk factor for bladder cancer and is classified by IARC as "carcinogenic to humans" (Group 1) [31]. A strong point is that we collected detailed information on smoking habits and took them into account in the statistical models. As expected from the literature, analysis showed that smoking is significantly associated with a risk of bladder cancer and that this risk increases significantly with the duration of smoking, the average number of cigarettes smoked and the number of pack-years [32-35]. Other non-occupational factors did not have any major effect.

Straight MWFs are mostly composed of mineral oils obtained from crude oil and may contain PAHs, the proportion of which varies depending on the degree of refining [36]. Up to the 1970s, mineral oils were untreated or slightly treated, and contained high concentrations of PAHs. In the mid-80s, in the United-States, the OSHA (Occupational Safety and Health Administration) pressurized cutting oil manufacturers to institute oil refining [10]. Implementation of refining probably decreased the amount of PAH in MWFs. Thus, refining has probably decreased PAH exposure, but our results still show an increased risk of bladder cancer for workers exposed to straight MWFs during the previous 25 years, which corresponds to exposure after the middle of the 1980s. We hypothesize that these results may also be due to the presence of PAHs in straight MWFs. Even if new lubricants are refined since the mid-80, straights MWFs may contain varying amount of $\mathrm{PAH}$, depending on 
the PAH enrichment when the MWFs are brought to high temperatures and depending on the degree of regeneration of waste oils.

One of the strengths of the study is that we increased the statistical power of our findings by making use of a pre-existing surrogate exposure estimate that was available for the whole cohort [5] and applying a counter-matching design for control selection [18]. Such a priori information is rare and the use of the counter-matching design is relatively original. The counter-matching design has rarely been used in occupational epidemiology [37], except in simulation studies.

In classical nested case-control studies, little information is provided in the model when case and matched controls have similar exposure levels. In contrast, the counter-matching design produces cases and controls with different exposure levels. The bias introduced by this sampling design is accounted for in the conditional multiple logistic regression models by using specific weighting [17]. The advantage of this design is that it improves statistical efficiency. According to Steenland [16], using 3 controls per case with a counter-matching design yields an increase of approximately 25 per cent in relative efficiency compared with random sampling, and it would be roughly equivalent to random sampling using 10 controls. However, in our study, this leads to increased numbers of duplicates in the selected controls. These reused controls belong to smaller risk sets and exposure groups within risk sets. This happens mostly in exposed groups as most cohort members are non-exposed.

Considering the blue and white collar status, only 11 workers (3.3\%) were white collars in our case-control study and $96 \%$ of the workers not exposed to straight MWF were blue collars. Therefore, this fact cannot entail a major residual confounding.

No cancer registry was available covering the area where the factories participating are located. Cases therefore had to be collected by contacting, inter alia, all 21 hospitals and 
clinics in the study area. Two clinics of significant size declined to participate in the study, potentially causing us to miss some eligible cases. However, some of them were retrievable if they were recorded in the national database of requests for exemption of medical expenses related to treatment of long-term diseases. Given that bladder cancer progresses slowly, we are confident that most of the cases were indeed registered in this file.

Over $40 \%$ of eligible cases could not be interviewed because there were deceased before interview, they declined to participate or they could not be contacted. No statistical difference in the surrogate exposure was detected between participant and not participant whatever the reason. Thus, the living or the participant status do not seem to bias the exposure assessment.

No atmospheric measurements were available for quantitative assessment of MWF exposure. Instead, the semi-quantitative assessment used was based on detailed exposure questionnaires including individual lifetime work histories and specific questionnaires focusing on all exposing tasks, as well as the firsthand knowledge of the working conditions in the companies of in-house occupational physicians and industrial hygienists, and the safety data sheets available from factories. This retrospective assessment based on the reported job history may be affected by recall bias but there is no reason why this should be different between cases and controls. Anyway, if the misclassification in exposure is nondifferential, this would entail an attenuation of the exposure-response relationship; this might explain the lack of association with the $\geq 25$ years old.In conclusion, our study highlights the association between the risk of developing bladder cancer and exposure to straight MWFs in the previous 25 years. Our study cannot exclude a relationship with exposure to soluble MWFs, but detects no relationship with synthetic MWFs. These results may be explained by the presence of carcinogens (such as PAH) in new or used mineral oils 
and other components of straight oils. Prevention therefore remains necessary in sectors using MWFs.

WORD COUNT: 4496 (4500) 


\section{CONTRIBUTORSHIP}

Each author has contributed to the submitted work as follow: RC and EB drafted the manuscript. RC and EB participated to the data collection. RC managed the data. RC and EB performed statistical analyses. EB reviewed the literature and designed the study. EB, MG, RC, PW and GH participated to the analysis plan. EB developed the job-specific questionnaires. EB managed the exposure assessment. All co-authors collaborated interactively, contributed to the interpretation of the results and discussion, read and approved the final manuscript. Each author believes that the manuscript represents honest work.

\section{ACKNOWLEDGMENTS}

This study would not have been possible without the participation of a significant number of people. We would like to thank the occupational physicians of the participating companies for their availability and invaluable help: Alain Bélanger, Yvon Bougant, Patrick Buisson, Alain Caron, Brigitte Courcot, Valérie Créteur, Jean-Loup Godron, and Jacques Ettlinger. We are grateful to Catherine Nisse, occupational physician and university lecturer for her advices. We thank all the cases and the controls who answered our questionnaires with great patience. We acknowledge the able participation of interviewers and data managers: Christine Bertrand, Mathieu Dziurla, Joëlle Genoud, Charlotte Girardey, Dominique Rousselle, and Monique Veillé. We are grateful to Pierre Goutet, industrial hygienist, for his valuable expertise and his excellent knowledge of the workplaces in steel-producing factories. We are also grateful to the directors of the medical information management departments of the hospitals and clinics from the "Nord-Pas de Calais" region (France) and 
the director of the "Direction Régionale du Service Médical Nord - Picardie" from the French health insurance, as well as their support staff, without whom this work could not have been done. We would like to thank the reviewers for their comments and suggestions which have significantly improved our paper.

\section{FUNDING}

No specific grant supported this research.

\section{COMPETING INTERESTS}

Conflict of interest: none declared. 


\section{REFERENCES}

1. Captage et traitement des aérosols de fluides de coupe. Guide de ventilation: INRS, 2005. Report: ED 972.

2. IARC. Monographs on the evaluation of carcinogenic risks to humans, Volume 77, Some industrial chemicals. Lyon, France: IARC (International Agency for Research on Cancer), 2000.

3. IARC. Monographs on the evaluation of carcinogenic risks to humans, Volume 34, Polynuclear aromatic compounds, Part 3: Industrial exposures in aluminum production, goal gasification, coke production, and iron and steel founding. Lyon, France: IARC (International Agency for Research on Cancer), 1984.

4. IARC. Monographs on the evaluation of carcinogenic risks to humans, Volume 33, Polynuclear Aromatic Compounds, Part 2: Carbon Blacks, Mineral Oils and Some Nitroarenes. Lyon, France: IARC (International Agency for Reasearch on Cancer), 1984.

5. Bourgkard E, Wild P, Courcot B, Diss M, Ettlinger J, Goutet P, et al. Lung cancer mortality and iron oxide exposure in a French steel-producing factory. Occup Environ Med. 2009;66(3):175-81.

6. Friesen MC, Costello S, Eisen EA. Quantitative exposure to metalworking fluids and bladder cancer incidence in a cohort of autoworkers. Am J Epidemiol. 2009;169(12):1471-8.

7. Colt JS, Friesen MC, Stewart PA, Donguk P, Johnson A, Schwenn M, et al. A case-control study of occupational exposure to metalworking fluids and bladder cancer risk among men. Occup Environ Med. 2014;71(10):667-74.

8. Cumberbatch MK, Cox A, Teare D, Catto JF. Contemporary occupational carcinogen exposure and bladder cancer: A systematic review and meta-analysis. JAMA Oncology. 2015;1(9):1282-90.

9. Weiderpass $\mathrm{E}$, Vainio $\mathrm{H}$. The need for further preventive measures for occupational bladder cancer. JAMA Oncology. 2015;1(9):1291-2.

10. Woskie SR, Virji MA, Hallock M, Smith TJ, Hammond SK. Summary of the findings from the exposure assessments for metalworking fluid mortality and morbidity studies. Appl Occup Environ Hyg. 2003;18(11):855-64.

11. Hery M, Conso F, Goutet P. En finir avec le cancer de la vessie en milieu professionnel. HSTINRS. 2006;203:79-83.

12. Les fluides de coupes. Etat des connaissances sur les usages, les expositions et les pratiques de gestion en France. Rapport d'étude: ANSES, Janvier 2012. Report.

13. Cancers de la vessie d'origine professionnelle. Utilisation industrielle d'agents étiologiques suspectés ou avérés. INRS, Décembre 2005. Report.

14. What you need to know about occupational exposure to metalworking fluids. NIOSH, 1998. Report: 98-116.

15. IARC. Monographs on the evaluation of carcinogenic risks to humans, Volume 100F: Chemical agents and related occupations. IARC (International Agency of Research on Cancer), 2012.

16. Steenland K, Deddens JA. Increased precision using countermatching in nested case-control studies. Epidemiology. 1997;8(3):238-42.

17. Cologne JB. Counterintuitive matching. Epidemiology. 1997;8(3):227-9.

18. Langholz B, Borgan O. Counter-Matching: A Stratified Nested Case-Control Sampling Method. Biometrika. 1995;82(1):69-79.

19. Warnez S, Goutet $P$, Herin F, Gonzalez M, Pairon JC, Conso F, et al. Cancérogènes de la vessie : présentation d'un questionnaire de tâches pour le repérage des expositions professionnelles. Archives des Maladies Professionnelles et de l'Environnement. 2011;72(3):231-9.

20. Langholz B, Goldstein L. Conditional logistic analysis of case-control studies with complex sampling. Biostatistics. 2001;2(1):63-84.

21. Rothman KJ. Induction and latent periods. Am J Epidemiol. 1981;114(2):253-9.

22. Checkoway H, Pearce N, Hickey JL, Dement JM. Latency analysis in occupational epidemiology. Arch Environ Health. 1990;45(2):95-100. 
23. Matsumoto K, Irie A, Satoh T, Kuruma H, Arakawa T, Baba S. Occupational bladder cancer: from cohort study to biologic molecular marker. Med Sci Monit. 2005;11(10):RA311-5.

24. Peace KE. The alternative hypothesis: one-sided or two-sided? J Clin Epidemiol. 1989;42(5):473-6.

25. Ruxton GD, Neuhäuser M. When should we use one-tailed hypothesis testing? Methods in Ecology and Evolution. 2010;1(2):114-7.

26. Richardson DB, Cole SR, Chu H, Langholz B. Lagging exposure information in cumulative exposure-response analyses. Am J Epidemiol. 2011;174(12):1416-22.

27. Colt JS, Karagas MR, Schwenn M, Baris D, Johnson A, Stewart $P$, et al. Occupation and bladder cancer in a population-based case-control study in Northern New England. Occup Environ Med. 2011;68(4):239-49.

28. Cancers de la vessie et risques professionnels. Avis d'experts. INRS, 2009. Report.

29. Kogevinas M, t Mannetje A, Cordier S, Ranft U, Gonzalez CA, Vineis P, et al. Occupation and bladder cancer among men in Western Europe. Cancer Causes Control. 2003;14(10):907-14.

30. Burger M, Catto JW, Dalbagni G, Grossman HB, Herr H, Karakiewicz P, et al. Epidemiology and risk factors of urothelial bladder cancer. Eur Urol. 2013;63(2):234-41.

31. IARC. Monographs on the evaluation of carcinogenic risks to humans, Volume 100E: Personal habits and indoor combustions. Lyon, France: IARC (International Agency for Research on Cancer), 2012.

32. Freedman ND, Silverman DT, Hollenbeck AR, Schatzkin A, Abnet CC. Association between smoking and risk of bladder cancer among men and women. Jama. 2011;306(7):737-45.

33. Brennan P, Bogillot O, Cordier S, Greiser E, Schill W, Vineis P, et al. Cigarette smoking and bladder cancer in men: a pooled analysis of 11 case-control studies. Int J Cancer. 2000;86(2):289-94.

34. Zeegers MP, Tan FE, Dorant E, van Den Brandt PA. The impact of characteristics of cigarette smoking on urinary tract cancer risk: a meta-analysis of epidemiologic studies. Cancer. 2000;89(3):630-9.

35. van Osch FH, Jochems SH, van Schooten FJ, Bryan RT, Zeegers MP. Quantified relations between exposure to tobacco smoking and bladder cancer risk: a meta-analysis of 89 observational studies. Int J Epidemiol. 2016;45(3):857-70.

36. Champmartin C. Estimation du potentiel cancérogène des huiles minérales régénérées. HSTINRS. 2012;227:3-10.

37. Drubay D, Caer-Lorho S, Laroche P, Laurier D, Rage E. Mortality from Circulatory System Diseases among French Uranium Miners: A Nested Case-Control Study. Radiat Res. 2015;183(5):55062. 


\begin{tabular}{|c|c|c|c|c|c|c|c|c|c|}
\hline & \multicolumn{3}{|c|}{ Cases $(n=84)$} & \multicolumn{3}{|c|}{ Controls $(n=251)$} & \multirow[b]{2}{*}{$\mathbf{O R}^{\mathrm{a}}$} & \multirow[b]{2}{*}{$95 \% \mathrm{Cl}$} & \multirow[b]{2}{*}{$P$ value } \\
\hline & No. & $\%$ & mean (sd) & No. & $\%$ & mean (sd) & & & \\
\hline Highest education level (years of schooling) & & & & & & & & & $0.449^{e}$ \\
\hline No qualification & 11 & 13.1 & & 27 & 10.8 & & 1.53 & $0.36-6.48$ & \\
\hline Less than secondary school (<15 years) & 46 & 54.7 & & 154 & 61.3 & & 1.48 & $0.56-3.93$ & \\
\hline Secondary school (18 years) & 13 & 15.5 & & 45 & 17.9 & & 1.25 & $0.40-3.89$ & \\
\hline Higher education ( $>18$ years) & 12 & 14.3 & & 24 & 9.6 & & 1 & & \\
\hline Missing & 2 & 2.4 & & 1 & 0.4 & & & & \\
\hline
\end{tabular}

\section{Smoking habits}

Smoking status

\section{Never smoker \\ Former smoker}

Current smoker

Duration of smoking (years)

Never smoker
$1-20$ years
$20-40$ years
$\geq 40$ years

Average cigarettes smoked per day

$\begin{array}{lcc}\text { Never smoker } & 9 & 10.7 \\ 1-10 & 11 & 13.1 \\ 10-20 & 42 & 50.0 \\ \geq 20 & 22 & 26.2\end{array}$

Pack-years

$\begin{array}{lcc}\text { Never smoker } & 9 & 10.7 \\ 1-20 & 24 & 28.6 \\ 20-40 & 38 & 45.2 \\ \geq 40 & 13 & 15.5\end{array}$

Time since smoking cessation

$\begin{array}{lcc}\text { Never smoker } & 9 & 16.9 \\ \geq 20 \text { years } & 8 & 15.1 \\ 10-20 \text { years } & 18 & 34.0 \\ <10 \text { years } & 18 & 34.0\end{array}$

Food consumption at the date of the interviewc

Fresh fruit

no $\quad 27 \quad 32.1$

yes $\quad 57 \quad 67.9$

Fresh vegetables

Sweeteners

Alcohol consumption

no $\quad 50 \quad 59.5$

yes $\quad 34 \quad 40.5$

no $\quad 73 \quad 86.9$

yes $\quad 11 \quad 13.1$

no $\quad 30 \quad 35.7$

yes $\quad 54 \quad 64.3$

Chronic bladder irritation $^{\mathrm{d}}$

no $\quad 80 \quad 95.2$

$\begin{array}{lll}\text { yes } \quad 4 & 4.8\end{array}$

Abdominopelvic radiography

no $\quad 57 \quad 67.9$

yes $\quad 27 \quad 32.1$

$\begin{array}{lll}\text { no } & 83 & 98.8\end{array}$

yes $\quad 1 \quad 1.2$
$31.7(10.4)$

\begin{tabular}{ll}
$76 \quad 30.3$ \\
\hline
\end{tabular}

$126 \quad 50.2$

$49 \quad 19.5$

$26.4(12.1)$

\begin{tabular}{ll}
$76 \quad 30.3$ \\
\hline
\end{tabular}

$44 \quad 17.5$

$109 \quad 43.4$

$22 \quad 8.8$

$18.1(9.6)$

\begin{tabular}{ll}
$76 \quad 30.3$ \\
\hline
\end{tabular}

$\begin{array}{ll}61 & 24.3\end{array}$

$\begin{array}{ll}67 & 26.7\end{array}$

$\begin{array}{ll}47 & 18.7\end{array}$

$28.4(18.6)$

$76 \quad 30.3$

$94 \quad 37.4$

$\begin{array}{ll}56 & 22.3\end{array}$

$25 \quad 10.0$

$12.9(8.1)$

$76 \quad 37.6$
-16

$52 \quad 25.8$

$\begin{array}{ll}33 & 16.3\end{array}$

$41 \quad 20.3$

$15.5(11.4)$

$22.1(19.7)$

$17.9(11.7)$ $<0.001^{\text {e }}$

$$
1
$$

$\begin{array}{lll}3.84 & 1.38-10.7 & 0.010\end{array}$

$10.87 \quad 3.39-34.9 \quad 0.000$

$<0.001^{\mathrm{f}}$

\section{1}

$\begin{array}{lll}2.62 & 0.72-9.59 & 0.145\end{array}$

$\begin{array}{lll}4.39 & 1.58-12.18 & 0.005\end{array}$

$15.29 \quad 4.29-54.51 \quad<0.001$

$0.002^{f}$

$$
1
$$

$\begin{array}{lll}1.78 & 0.52-6.16 & 0.361\end{array}$

$\begin{array}{lll}6.66 & 2.23-19.90 \quad 0.001\end{array}$

$\begin{array}{lll}7.88 & 2.48-25.03 \quad<0.001\end{array}$

$<0.001^{\text {f }}$

$$
1
$$

$\begin{array}{lll}2.10 & 0.69-6.39 & 0.191\end{array}$

$8.45 \quad 2.90-24.64<0.001$

$9.37 \quad 2.60-33.85 \quad 0.001$

$0.002^{f}$

1

$\begin{array}{lll}2.60 & 0.70-9.72 & 0.155\end{array}$

$\begin{array}{lll}4.87 & 1.10-21.47 & 0.036\end{array}$

$\begin{array}{lll}5.39 & 1.33-21.95 & 0.019\end{array}$

$\begin{array}{ccccc}64 & 25.5 & 1 & & \\ 187 & 74.5 & 0.61 & 0.31-1.23 & 0.172 \\ 104 & 41.4 & 1 & & \\ 147 & 58.6 & 0.52 & 0.26-1.03 & 0.061 \\ 209 & 83.3 & 1 & & \\ 42 & 16.7 & 0.86 & 0.35-2.10 & 0.743 \\ 87 & 34.7 & 1 & & \\ 164 & 65.3 & 0.68 & 0.34-1.38 & 0.289 \\ 233 & 92.8 & 1 & & \\ 18 & 7.2 & 0.81 & 0.19-3.37 & 0.773 \\ 167 & 66.5 & 1 & & \\ 84 & 33.5 & 0.62 & 0.30-1.27 & 0.190 \\ 240 & 95.6 & 1 & & \\ 11 & 4.4 & 0.24 & 0.02-2.43 & 0.226\end{array}$


Abbreviations: PAHs, Polycyclic Aromatic Hydrocarbons; MWFs, metalworking fluids; OR, Odds Ratio; $95 \% \mathrm{Cl}$, 95\% confidence intervals a Conditional logistic regression, adapted to counter-matching

b Calulations take into account a 5 year-lag

c Daily consumption

${ }^{d}$ Urinary schistosomiasis and urolithiasis

e From trend analysis

${ }^{f}$ From continous data 
Table 2 Exposure to different types of MWF, PAH, Chlorinated solvents and Diesel exhaust fumes, according to 3 continuous exposure indices, for cases and controls

\begin{tabular}{|c|c|c|c|c|c|c|c|c|c|c|}
\hline & \multicolumn{5}{|c|}{ Cases $(n=84)$} & \multicolumn{5}{|c|}{ Controls $(n=251)$} \\
\hline & & & $\begin{array}{l}\text { Duration } \\
\text { (year) }\end{array}$ & $\begin{array}{c}\text { Frequency-weighted } \\
\text { duration } \\
\text { (full-time equivalent } \\
\text { year) }\end{array}$ & $\begin{array}{l}\text { Cumulative index } \\
\text { (intensity.year) }\end{array}$ & & & $\begin{array}{l}\text { Duration } \\
\text { (year) }\end{array}$ & $\begin{array}{c}\text { Frequency-weighted } \\
\text { duration } \\
\text { (full-time equivalent } \\
\text { year) }\end{array}$ & $\begin{array}{l}\text { Cumulative index } \\
\text { (intensity.year) }\end{array}$ \\
\hline & No. & $\%$ & median $(\min -\max )^{\mathrm{a}}$ & median $(\min -\max )^{\mathrm{a}}$ & median $(\min -\max )^{\mathrm{a}}$ & No. & $\%$ & median $(\min -\max )^{\mathrm{a}}$ & median $(\min -\max )^{\mathrm{a}}$ & median $(\min -\max )^{\mathrm{a}}$ \\
\hline \multicolumn{11}{|l|}{ Straight MWFs } \\
\hline 5-25-year time-window & 13 & 15.5 & $14.6(0.9-20.0)$ & $1(0.0-13.7)$ & $1.6(0.0-13.7)$ & 37 & 14.7 & $7.3(0.9-20.0)$ & $0.7(0.0-13.8)$ & $0.7(0.0-27.6)$ \\
\hline$\geq 25$-year time-window & 21 & 25.0 & $4.1(0.5-23.3)$ & $0.4(0.0-10.8)$ & $0.4(0.0-10.8)$ & 82 & 32.7 & $5.9(0.7-23.2)$ & $1.0(0.0-14.4)$ & $1.1(0.0-28.8)$ \\
\hline \multicolumn{11}{|l|}{ Soluble MWFs } \\
\hline 5-25-year time-window & 14 & 16.7 & $14.6(0.8-20.0)$ & $1.6(0.0-13.7)$ & $1.8(0.1-21.3)$ & 57 & 22.7 & $12.4(0.3-20.2)$ & $1.1(0.0-15.0)$ & $1.9(0.0-27.6)$ \\
\hline$\geq 25$-year time-window & 14 & 16.7 & $5.1(0.5-14.5)$ & $0.8(0.0-10.8)$ & $1.2(0.1-10.8)$ & 83 & 33.1 & $7.3(0.2-25.3)$ & $1.3(0.0-18.2)$ & $2.3(0.0-36.4)$ \\
\hline \multicolumn{11}{|l|}{ Synthetic MWFs } \\
\hline 5-25-year time-window & 4 & 4.8 & $11.2(1.1-20.0)$ & $1(0.8-1.8)$ & $1.3(1-1.8)$ & 15 & 6.0 & $7.4(0.8-20.0)$ & $1.9(0.0-15.0)$ & $1.9(0.0-25.7)$ \\
\hline$\geq 25$-year time-window & 5 & 6.0 & $4.6(2.7-9.6)$ & $0.4(0.0-7.2)$ & $0.4(0.1-7.2)$ & 23 & 9.2 & $9.6(0.9-25.7)$ & $2.7(0.2-18.2)$ & $4.1(0.2-36.4)$ \\
\hline $\mathrm{PAH}^{\mathrm{b}, \mathrm{c}}$ & 34 & 40.5 & $14.3(1.1-33.4)$ & $0.7(0.0-22.9)$ & $1.6(0.0-45.9)$ & 80 & 31.9 & $7.5(0.3-39.6)$ & $0.9(0.0-24.6)$ & $1.2(0.0-73.9)$ \\
\hline Chlorinated solvent ${ }^{b}$ & 43 & 51.2 & $21.4(1.1-37.3)$ & $1.0(0.1-28.0)$ & $1.1(0.1-56.0)$ & 136 & 54.2 & $16.5(0.2-39.6)$ & $0.9(0.0-8.7)$ & $1.0(0.0-17.5)$ \\
\hline Diesel exhaust fumes $s^{b, d}$ & 13 & 15.5 & $13.0(3.3-36.1)$ & - & - & 38 & 15.1 & $10.1(0.6-39.2)$ & - & - \\
\hline
\end{tabular}

Abbreviations: PAHs, Polycyclic Aromatic Hydrocarbons; MWFs, metalworking fluids

${ }^{a}$ Workers who were never exposed were excluded when calculating the median, the minimum and the maximum

${ }^{\mathrm{b}}$ Calculated with a 5-year lag

cPAHs except MWFs

${ }^{\mathrm{d}}$ Frequency and intensity not determined 
Table 3 Estimated odds ratio for the association between bladder cancer and MWF exposure for 3 continuous exposure indices, adjusted for duration of smoking, average cigarettes smoked per day and time since smoking cessation

\begin{tabular}{|c|c|c|c|c|c|c|c|c|c|}
\hline & \multicolumn{3}{|c|}{$\begin{array}{l}\text { Duration } \\
\text { (year) }\end{array}$} & \multicolumn{3}{|c|}{$\begin{array}{l}\text { Frequency-weighted duration } \\
\text { (full-time equivalent year) }\end{array}$} & \multicolumn{3}{|c|}{$\begin{array}{l}\text { Cumulative index } \\
\text { (intensity.year) }\end{array}$} \\
\hline & $\mathbf{O R}^{\mathrm{a}}$ & $95 \% \mathrm{Cl}$ & $P$ value $^{\mathrm{b}}$ & $\mathbf{O R}^{\mathrm{a}}$ & $95 \% \mathrm{Cl}$ & $P$ value $^{\mathrm{b}}$ & $\mathrm{OR}^{\mathrm{a}}$ & $95 \% \mathrm{Cl}$ & $P$ value $^{\mathrm{b}}$ \\
\hline \multicolumn{10}{|l|}{ Straight MWFs } \\
\hline 5-25-year time-window & 1.12 & $1.03-1.22$ & 0.005 & 1.36 & $1.02-1.82$ & 0.019 & 1.24 & $1.00-1.53$ & 0.022 \\
\hline$\geq 25$-year time-window & 0.97 & $0.89-1.06$ & 0.721 & 0.90 & $0.66-1.22$ & 0.756 & 0.89 & $0.71-1.11$ & 0.859 \\
\hline \multicolumn{10}{|l|}{ Soluble MWFs } \\
\hline 5-25-year time-window & 1.08 & $1.01-1.16$ & 0.011 & 1.12 & $0.96-1.30$ & 0.076 & 1.14 & $1.01-1.28$ & 0.014 \\
\hline$\geq 25$-year time-window & 0.91 & $0.82-1.01$ & 0.961 & 0.91 & $0.73-1.13$ & 0.808 & 0.90 & $0.78-1.05$ & 0.915 \\
\hline \multicolumn{10}{|l|}{ Synthetic MWFs } \\
\hline 5-25-year time-window & 1.02 & $0.86-1.21$ & 0.400 & 0.81 & $0.47-1.38$ & 0.785 & 0.90 & $0.60-1.36$ & 0.689 \\
\hline$\geq 25$-year time-window & 0.95 & $0.80-1.13$ & 0.726 & 1.13 & $0.86-1.49$ & 0.181 & 1.03 & $0.84-1.26$ & 0.388 \\
\hline
\end{tabular}

Abbreviations: MWFs, metalworking fluids; OR, Odds Ratio; $95 \% \mathrm{Cl}, 95 \%$ confidence intervals

a Conditional logistic regression adapted to counter-matching, for each type of MWFs

${ }^{b}$ One-tailed p-value 
Table 4 Estimated odds ratio for the association between bladder cancer and occupational exposure for 3 continuous exposure indices, adjusted for duration of smoking, average cigarettes smoked per day and time since smoking cessation, with a 5 year-lag.

\begin{tabular}{|c|c|c|c|c|c|c|c|c|c|}
\hline & \multicolumn{3}{|c|}{$\begin{array}{l}\text { Duration } \\
\text { (year) }\end{array}$} & \multicolumn{3}{|c|}{$\begin{array}{l}\text { Frequency-weighted duration } \\
\text { (full-time equivalent year) }\end{array}$} & \multicolumn{3}{|c|}{$\begin{array}{l}\text { Cumulative index } \\
\text { (intensity.year) }\end{array}$} \\
\hline & $\mathrm{OR}^{\mathrm{a}}$ & $95 \% \mathrm{Cl}$ & $\begin{array}{c}P \\
\text { value }^{\mathrm{b}}\end{array}$ & $\mathrm{OR}^{\mathrm{a}}$ & $95 \% \mathrm{Cl}$ & $P$ value ${ }^{\mathrm{b}}$ & $\mathrm{OR}^{\mathrm{a}}$ & $95 \% \mathrm{Cl}$ & $P$ value \\
\hline $\mathrm{PAHs}^{\mathrm{c}}$ & 1.05 & $1.01-1.09$ & 0.004 & 1.12 & $1.03-1.22$ & 0.005 & 1.04 & $1.00-1.08$ & 0.025 \\
\hline Chlorinated solvent & 1.02 & $1.00-1.05$ & 0.046 & 1.13 & $0.99-1.28$ & 0.037 & 1.07 & $0.99-1.16$ & 0.054 \\
\hline Diesel exhaust fumes ${ }^{d}$ & 1.02 & $0.97-1.07$ & 0.190 & - & - & - & - & - & - \\
\hline
\end{tabular}

Abbreviations: PAHs, Polycyclic Aromatic Hydrocarbons; MWFs, metalworking fluids; OR, Odds Ratio; $95 \% \mathrm{Cl}$, 95\% confidence intervals

${ }^{a}$ Each $\mathrm{OR}$ is the result of conditional logistic regression, adapted to counter-matching

${ }^{b}$ One-tailed p-value

c PAHs except in MWFs

${ }^{d}$ Frequency and intensity not determined 
Table 5 Estimated odds ratio for the association between bladder cancer and occupational exposure to MWFs, PAHs, and smoking from three multiple conditional logistic regressions adapted to the counter-matching design ${ }^{a}$

\begin{tabular}{|c|c|c|c|c|c|c|c|c|c|}
\hline & \multicolumn{3}{|c|}{$\begin{array}{l}\text { Duration } \\
\text { (year) }\end{array}$} & \multicolumn{3}{|c|}{$\begin{array}{l}\text { Frequency-weighted duration } \\
\text { (full-time equivalent year) }\end{array}$} & \multicolumn{3}{|c|}{$\begin{array}{l}\text { Cumulative index } \\
\text { (intensity.year) }\end{array}$} \\
\hline & OR & $95 \% \mathrm{Cl}$ & $P$ value ${ }^{\mathrm{b}}$ & OR & $95 \% \mathrm{Cl}$ & $P$ value ${ }^{b}$ & OR & $95 \% \mathrm{Cl}$ & $P$ value $^{\mathrm{b}}$ \\
\hline \multicolumn{10}{|l|}{ Straight MWFs } \\
\hline 5-25-year time-window & 1.13 & $1.02-1.25$ & 0.012 & 1.44 & $0.97-2.14$ & 0.034 & 1.18 & $0.92-1.51$ & 0.096 \\
\hline$\geq 25$-year time-window & 0.99 & $0.89-1.10$ & 0.558 & 0.94 & $0.66-1.34$ & 0.638 & 0.93 & $0.72-1.19$ & 0.724 \\
\hline \multicolumn{10}{|l|}{ Soluble MWFs } \\
\hline 5-25-year time-window & 1.06 & $0.98-1.15$ & 0.059 & 1.07 & $0.86-1.33$ & 0.285 & 1.12 & $0.97-1.30$ & 0.055 \\
\hline$\geq 25$-year time-window & 0.87 & $0.76-0.99$ & 0.980 & 0.82 & $0.61-1.10$ & 0.912 & 0.90 & $0.74-1.10$ & 0.853 \\
\hline \multicolumn{10}{|l|}{ Synthetic MWFs } \\
\hline 5-25-year time-window & 0.96 & $0.76-1.23$ & 0.614 & 0.82 & $0.40-1.72$ & 0.698 & 0.82 & $0.52-1.28$ & 0.811 \\
\hline$\geq 25$-year time-window & 0.96 & $0.78-1.18$ & 0.656 & 1.31 & $0.88-1.95$ & 0.094 & 1.15 & $0.87-1.50$ & 0.163 \\
\hline $\mathrm{PAHs}^{\mathrm{c}}$ & 1.05 & 1.01-1.09 & 0.005 & 1.12 & $1.03-1.22$ & 0.004 & 1.04 & $1.00-1.08$ & 0.019 \\
\hline Duration of smoking & 1.04 & $1.01-1.08$ & 0.003 & 1.04 & $1.01-1.08$ & 0.002 & 1.05 & $1.02-1.08$ & 0.001 \\
\hline Average cigarettes smoked per day & 1.02 & $0.99-1.05$ & 0.131 & 1.02 & $0.99-1.06$ & 0.091 & 1.02 & $0.99-1.06$ & 0.089 \\
\hline Time since smoking cessation & 0.97 & $0.94-1.01$ & 0.088 & 0.98 & $0.94-1.01$ & 0.102 & 0.98 & $0.94-1.01$ & 0.114 \\
\hline
\end{tabular}

Abbreviations: PAHs, Polycyclic Aromatic Hydrocarbons; MWFs, metalworking fluids; OR, Odds Ratio; $95 \% \mathrm{Cl}, 95 \%$ confidence intervals

a Calculations consider a 5 year-lag

${ }^{b}$ One-tailed p-value

c PAHs except in MWFs, same method of calculation as the MWF metric considered in the model 